\title{
A biological tool to assess flow connectivity in reference temporary streams from the Mediterranean Basin
}

Cid N. ${ }^{1}$, Verkaik I. ${ }^{1}$, García-Roger E.M. ${ }^{1,5}$, Rieradevall M. ${ }^{1}$, Bonada N. ${ }^{1}$, Sánchez-Montoya M.M. ${ }^{2,6}$, Gómez R. ${ }^{2}$, Suárez M.L. ${ }^{2}$, Vidal-Abarca M.R. ${ }^{2}$, Demartini D. ${ }^{3}$, Buffagni A. ${ }^{3}$, Erba S. ${ }^{3}$, Karaouzas I. ${ }^{4}$, Skoulikidis N. ${ }^{4}$, Prat N. ${ }^{1}$

\footnotetext{
${ }^{1}$ Grup de Recerca “Freshwater Ecology and Management (FEM)”, Departament d'Ecologia. Universitat de Barcelona, Catalonia, Spain

${ }^{2}$ Department of Ecology and Hydrology. Regional Campus of International Excellence "Campus Mare Nostrum”-University of Murcia. Spain.

${ }^{3}$ Instituto di Ricerca Sulle Acque (CNR-IRSA), Italy

${ }^{4}$ Hellenic Center for Marine Research (HCMR), Greece

${ }^{5}$ Institut Cavanilles de Biodiversitat i Biologia Evolutiva. Universitat de València, Spain

${ }^{6}$ Leibniz-Institute of Freshwater Ecology and Inland Fisheries (IGB), Berlin, Germany
}

\begin{abstract}
Many streams in the Mediterranean Basin have temporary flow regimes. While timing for seasonal drought is predictable, they undergo strong inter-annual variability in flow intensity. This high hydrological variability and associated ecological responses challenge the ecological status assessment of temporary streams, particularly when setting reference conditions. This study examined the effects of flow connectivity in aquatic macroinvertebrates from seven reference temporary streams across the Mediterranean Basin where hydrological variability and flow conditions are well studied. We tested for the effect of flow cessation on two streamflow indices and on community composition, and, by performing random forest and classification tree analyses we identified important biological predictors for classifying the aquatic state either as flowing or disconnected pools. Flow cessation was critical for one of the streamflow indices studied and for community composition. Macroinvertebrate families found to be important for classifying the aquatic state were Hydrophilidae, Simuliidae, Hydropsychidae, Planorbiidae, Heptageniidae and Gerridae. For biological traits, trait categories associated to feeding habits, food, locomotion and substrate relation were the most important and provided more accurate predictions compared to taxonomy. A combination of selected metrics and associated thresholds based
\end{abstract}


on the most important biological predictors (i.e. Bio-AS Tool) were proposed in order to assess the aquatic state in reference temporary streams, especially in the absence of hydrological data. Although further development is needed, the tool can be of particular interest for monitoring, restoration, and conservation purposes, representing an important step towards an adequate management of temporary rivers not only in the Mediterranean Basin but also in other regions vulnerable to the effects of climate change.

Keywords: biological traits, macroinvertebrates, Mediterranean Basin, hydrological variability, reference conditions, ecological status 


\section{Introduction}

Temporary streams are those watercourses that undergo a recurrent cessation of flow or the complete drying of their channel (Williams, 2006), including non-perennial, seasonal, intermittent, episodic or ephemeral flow regimes (Datry et al., 2014a; Datry, Larned \& Tockner, 2014). Although temporary streams are very common in many regions of the world, historically they have been neglected by ecologists (Larned et al., 2010) and there remains a general lack of understanding, protecting, and managing this type of freshwater ecosystem (Acuña et al., 2014). In Europe, one of the challenges of the Water Framework Directive (WFD) is the ecological status assessment of temporary streams (Nikolaidis et al., 2013).

The hydrological variability of temporary streams and associated ecological responses has hampered the assessment of their ecological status because tools and metrics have been primarily developed for perennial streams (Sheldon, 2005; Fritz, Johnson \& Walters, 2008; Munné \& Prat, 2011). The cessation of flow represents a critical stage for the river ecosystem where abrupt changes in habitat availability and quality occur, together with associated changes in aquatic communities (Boulton, 2003). Once connectivity is lost and pools become isolated, random and less predictive changes of the environmental conditions may occur, altering biological communities. For this reason, biological quality assessments using available standardized methods should be performed when stream mesohabitats (e.g. riffles, pools) are still connected (Bonada et al., 2006; Buffagni, Armanini \& Erba, 2009; Buffagni, Erba \&Armanini, 2010; Prat et al., 2014). In this context, several studies have been devoted to characterizing not only a given hydrological state but also all the different stages that a watercourse may undergo (Boulton, 2003; Fritz, Johnson \& Walters, 2006). Recently, Gallart et al. (2012) developed a method based on rainfall-runoff models to describe six ecologically relevant aquatic states (AS) representing the different hydrological conditions of a temporary stream reach, ranging from a flood state (i.e. hyperrheic) to the complete absence of surface and subsurface water (i.e. edaphic). This approach resulted in a successful precondition classification tool, named AS-Tool, for the establishment of ecological status, and became a key element of the recently developed integrated assessment protocol for temporary streams in the Mediterranean Basin (i.e. MIRAGE- toolbox, see Prat et al., 2014). This tool provides information on the frequency of occurrence of aquatic states before the sampling and therefore allows to decide whether biological quality may be measured by the same methods as in permanent streams or not. However, the application of the AS-Tool can be hampered by 
the absence of gauging stations, the lack of long-term environmental data, or by the influence of local factors such as streambed composition (e.g. bedrock or sand and gravel substrate) not captured by the models. For those cases where the AS-tool cannot be applied, the MIRAGEtoolbox aimed at providing an alternative method, named BioAS-Tool, based on the biological assessment of aquatic states (Fig. 1).

On the one hand, macroinvertebrates are widely used as indicators of stream biological quality, including the assessment of flow conditions (Extence, Balbi \& Chadd, 1999; Gore, Layzer \& Mead, 2001; Suren \& Jowett, 2006; Merigaux et al., 2009; Dunbar et al., 2010). On the other hand, many biomonitoring programmes conducted in streams from the Mediterranean Basin have produced a large number of macroinvertebrate datasets, whereas hydrological data of the stream in question may be absent. Thus, the response of macroinvertebrate communities to changes in river flow may offer a surrogate method for assessing the aquatic state of temporary streams on the basis that macroinvertebrate communities continuously integrate local flow conditions. For example, the ratio EPT/OCH (i.e. the ratio between Ephemeroptera, Plecoptera and Trichoptera taxa, and Odonata, Coleoptera and Hemiptera taxa) has been used to describe stream flow connectivity in regions with Mediterranean climate (Bonada et al., 2006). Additionally, from a community trait perspective, temporary streams are characterized by macroinvertebrate communities with strategies to cope with extreme hydrological conditions of flooding and drying, as different authors have shown (Williams, 1996; Bonada, Rieradevall \& Prat, 2007a; Arscott et al., 2010; Robson, Chester \&Austin, 2011; García-Roger et al., 2013; Vidal- Abarca et al., 2013; Chessman, 2015). These traits explain how organisms respond to environmental constrains and thereby facilitate formulating a priori predictions (Statzner \& Bêche, 2010). Thus, biological traits might be useful as indicators of flow connectivity, especially when considering large spatial scales (Statzner et al., 2001; Bonada, Dolédec \& Statzner, 2007).

Climate change predictions in Europe indicate that in particular the Mediterranean region will face severe stream flow deficits (Schneider et al., 2013; Forzieri et al., 2014), increasing the vulnerability of temporary rivers (Acuña et al., 2014; Datry et al., 2014b) and causing permanent ones to become temporary (Datry, 2012; Schneider et al., 2013). Such predicted changes have important implications for the ways in which we currently assess ecological status due to potential shifts in river typology, community composition and, consequently, reference condition baselines (Logez \& Pont, 2012; Pace, Bonada \& Prat, 
2013). Thus, there is an urgent need to assess and monitor hydrological and ecological conditions in reference sites in the face of climate change (EC, 2009; Wilby et al., 2010), including reference temporary streams.

The aim of this study was to develop a biological tool (i.e. BioAS-Tool) to classify the aquatic state of temporary streams either as flowing (F) or disconnected pools (DP) using the taxonomic and biological trait composition of the macroinvertebrate community as predictors. Macroinvertebrates from seven reference streams across the Mediterranean Basin were sampled during three years in different seasons, incorporating biogeographic, seasonal, and inter-annual differences in community composition. The rigor of the development of the BioAS-Tool is based on using macroinvertebrate samples from reference streams where hydrological variability and aquatic state classification are well studied (Gallart et al., 2012). The tool aims to enable users to predict the aquatic state that a stream reach has been subjected to before the sample was taken, and thereby to adequately assess the ecological status. Firstly, we assessed the effect of flow connectivity in traditional flow bioassessment metrics. Secondly, we examined shifts in community composition to select those biological predictors that best classified flow connectivity. Finally, we proposed a set of potential novel metrics that constitute the BioAS-Tool.

\section{Methods}

Study sites

This study was conducted in seven streams throughout the European Mediterranean Basin (Fig. 2). The streams belong to five different circum-Mediterranean eco-regions according to the classification by Illies (1978): Ibero-Macaronesian region (Enxöe and Taibilla), Pyrenees (Vallcebre), Western plains (La Vêne), Italy, Corsica and Malta region (Biferno and Candelaro), and Hellenic Western Balkan region (Evrotas), thus providing sufficient variation of the aquatic macroinvertebrate communities at regional scale. All streams were subject of study under the EU-funded research project MIRAGE (Mediterranean Intermittent River ManAGEment) and classified as reference sites, supported by Sánchez-Montoya et al. (2012) and Prat et al. (2014). All these streams are considered as temporary according to the definition provided in this special issue (see articles in this special issue). Frequency graphs 
of the aquatic states for some of streams studied here are described in Gallart et al. (2012) and (Girolamo et al., 2014). Further details are shown in García-Roger et al. (2013).

\section{Sample collection and processing}

In each stream, we surveyed $1-3$ reaches measuring $25-30 \mathrm{~m}$ in spring and summer 2009 and 2010, autumn 2010, and winter 2011 (Table 1). In each reach, the sampling integrated all mesohabitats (i.e., riffles and pools) and microhabitats (i.e., different mineral and organicbased substrata) (see García-Roger et al., 2013). We sampled aquatic macroinvertebrate communities using a Surber (dimensions adapted to stream size: ranging from 0.0025 to 0.09 $\mathrm{m}^{2}$; and $250 \mu \mathrm{m}$ mesh), and preserved them in $4 \%$ formaldehyde to be identified in the laboratory. The identification of macroinvertebrates was done at family level, except for Copepoda, Hydracarina, Ostracoda and Oligochaeta, according to Tachet et al. (2010).

\section{Flow connectivity}

Following the concept of critical thresholds in flow conditions (Boulton, 2003), the degree of flow connectivity was classified into flowing (F) or disconnected pools (DP) based on the aquatic states obtained from hydrograms in the same streams by Gallart et al. (2012) that were used to develop the AS-Tool (Fig. 3). In the study of Gallart et al. (2012), six ecologically relevant aquatic states were defined to represent the different hydrological conditions of a temporary stream reach (i.e. Hyperrheic, flood state; Eurheic, abundant riffles; Oligorheic, connected pools; Arheic; disconnected pools; Hyporheic, no surface water but wet alluvium; and edaphic, dry alluvium). However, we used a binary aquatic state classification because F and DP encompass the broader aquatic states and indicate the loss of longitudinal flow connectivity. In this sense, F includes the Eurheic and Oligorheic states, while DP corresponds to Arheic. Moreover, well-established aquatic macroinvertebrate communities have been described in F and DP, compared to the heavily disturbed hyperreic state or dry state (Datry, 2012).

To confirm the hydrological classification obtained from hydrograms we used direct field observations on the aquatic states synchronous with water discharge measurements. Discharge (D) was obtained from automatic gauging stations or, alternatively, by measuring channel width and taking water velocity at a minimum of five equal subsections of the reach 
selected. In total, 27 samples corresponded to F and 8 to DP and at least one stream per country presented one reach in DP conditions (Table 1). Examples of the aquatic state classification and threshold flow values that separate their occurrence at different stream reaches of the present study are shown in Table 2. As a general rule for all the streams not present in Table 2, when $\mathrm{D}>0.51 \cdot \mathrm{s}^{-1}$ the reach was classified into $\mathrm{F}$ while if $\mathrm{D} \leq 0.51 \cdot \mathrm{s}^{-1}$ into DP.

\section{Biological traits}

Biological trait data were originally obtained from Tachet et al. (2010). We used 61 categories of 11 biological traits, which describe macroinvertebrate morphology (maximum potential size), life-cycle features (duration, number of cycles per year, aquatic stages), reproduction, resilience or resistance abilities (dispersal, resistant forms, locomotion), physiology (respiration) and feeding behaviours (food and feeding habits).

Based on the database at genera level with their affinity to each trait category using a fuzzy coding approach (Chevenet, Dolédec \&Chessel, 1994, Bonada et al. 2007a, Mellado et al., 2008), we computed and re-scaled (to a 1-5 scale) the average affinity to a family level. Although the common level of taxonomical resolution at which studies on traits in aquatic macroinvertebrates are performed is the genera level, it has been demonstrated that an accurate description of trait abundance and diversity may be achieved by identification at higher taxonomical levels (i.e. family), no matter the spatial scale (Dolédec, Olivier \& Statzner, 2000; Gayraud et al. 2003). Furthermore, the effect of the level of taxonomic resolution (family $c f$. genus) on the structure of biological trait data corresponding to a subset of the streams used in the present study was previously tested by García-Roger et al. (2013) and was small enough to be neglected. Considering the purpose of the present study and given that most biomonitoring metrics use family-level identifications, we used family level to compute all community metrics. This coarse approximation will also allow application of the tool developed here to other family-level datasets from biomonitoring programmes in the Mediterranean Basin or other regions (Munné \& Prat, 2009, 2011).

\section{Community metrics}


Two stream flow indices for rivers commonly used in bioassessment in the studied area were calculated: the ratio $\mathrm{EPT} /(\mathrm{EPT}+\mathrm{OCH})$ (where EPT stands for sum of number of Ephemeroptera, Plecoptera and Trichoptera and $\mathrm{OCH}$ the sum of number of Odonata, Coleoptera and Hemiptera, all at family level) and the LIFE-F index (Lotic-invertebrate Index for Flow Evaluation; Extence et al., 1999). The ratio (EPT/(EPT+OCH)) has been used to assess seasonal changes due to flow variation (Bonada et al., 2006). The LIFE-F index is based on British macroinvertebrate preferences to flow velocity and has been used to assess macroinvertebrate community response to flow variability (Extence et al., 1999). These indices were tested for differences between $\mathrm{F}$ and DP for each community metric using nonparametric Kruskal-Wallis tests.

\section{BioAS-Tool development}

The development of the BioAS-Tool consisted of a two-step approach that involved the performance of two different classification methods using macroinvertebrate data as predictors (Fig. 4). Firstly, we used the Random Forest (RF) algorithm (Breiman, 2001) to select the subset of biological predictors that best classified flow connectivity and propose them as potential new metrics. Secondly, we used classification tree (Ctree) analyses (Hothorn et al. 2014) to obtain thresholds for the new metrics and the existing metrics known to respond to flow conditions according to the literature (i.e. LIFE-F index and $\mathrm{EPT} /(\mathrm{EPT}+\mathrm{OCH}))$.

\section{Random Forest analyses}

$\mathrm{RF}$ is a non-parametric classifier method that uses bootstrap samples of the data with replacement to grow a set of decision trees, allowing selection of the most popular assigned class, and thus producing a significant increase in classification accuracy (Liaw \& Wiener, 2002). Compared to other traditional statistical analyses, RF cannot be over-fit and are especially useful when there are few sample sites and many possible predictors (Breiman, 2001; Cutler et al., 2007), as is the case in this study. Furthermore, RF provides measures of the importance of predictor variables, which can be used to understand the contribution of specific variables in a classification. Predictors can be considered informative if their variable importance value is above the absolute value of the lowest scoring variable and noninformative if their importance value varies randomly around zero (Strobl, Hothorn \& Zeleis, 
2009). We built two RF models based on taxonomy and traits using the log-transformed macroinvertebrate family abundances and their relative abundance of each category per trait as predictors, respectively, obtaining the predictor importance. The subset of most important macroinvertebrate families and trait categories were therefore proposed as potential novel metrics to classify flow connectivity, as well as a multimetric index based on the sum of the proportion of each selected trait category. Furthermore, for the case of the trait-based RF model, we checked if the subset of trait categories selected as the most important predictors were within those that we a priori expected to predict flow connectivity (see Table 3 ).

Classification Tree analyses and selection of metrics

Ctree is a non-parametric method of recursive binary partitioning that creates splits in those input variables presenting (individually) the highest $P$ relative to the response variable (Hothorn et al., 2014). Unlike RF, Ctrees provide threshold values for each significant variable, thus facilitating ecological interpretation. We built one Ctree for each metric proposed and also for the existing metrics, and we tested for their performance in classifying flow connectivity. In order to assess each Ctree's performance we calculated: (1) total percentage of classes correctly classified, (2) percentage of F correctly classified (3) percentage of DP correctly classified, and (4) Cohen's kappa. Cohen's kappa ( $\kappa)$ is a measure of the agreement between predictions and actual values, corrected for agreement due to chance alone. For $\kappa$, values of $0.0-0.4$ are considered to indicate slight to fair model performance, values of 0.4-0.6 moderate, $0.6-0.8$ substantial and 0.8-1.0 almost perfect (Manel, Williams \& Ormerod, 2001). We kept only those metrics with at least moderate performance $(\kappa>0.4)$ and use them for validation with the additional dataset (see next section).

\section{BioAS-Tool validation}

The applicability of the BioAS-Tool was tested using external data from other reference temporary streams located in the Mediterranean Basin not initially included in the model building. Data were obtained from different biomonitoring programmes carried out in three 3 regions. The large part of the dataset came from the FEM (Freshwater Ecology and Management) research group in the Department of Ecology at the University of Barcelona (Catalonia) and included records from 189 sites collected between 1998 and 2010 
(http://ecobill.diba.cat). Another dataset was obtained from the Istituto di Ricerca Sulle Acque (CNR-IRSA, Italy) and included records from 8 sites sampled in 2004 in Sardinia. Finally, a last dataset was provided by the Department of Ecology and Hydrology at the University of Murcia and included records from 21 sites sampled in 2003. In total, the validation dataset consisted of 218 stream reaches with their corresponding aquatic state (F or DP) obtained from direct field observations. The methodology used in 3 regions are similar and the samples were obtained using standardized monitoring protocols (see SánchezMontoya et al., 2009), and contained semi-quantitative macroinvertebrate information at the family level.

All statistical analyses and graphs were carried out using R open-source software ( $R$ Development Core Team, 2014) using ade4 (Dray \& Dufour, 2007), vegan (Oksanen et al., 2014), party (Hothorn et al., 2014), and ved (Meyer et al., 2013) packages.

\section{Results}

Effect of flow connectivity on streamflow biological indices

The ratio EPT/(EPT+OCH) presented lower values in DP compared to F, but only the LIFE-F index showed the significant differences between F and DP $(P<0.01)$ (Fig. 5).

\section{Biological predictors of flow connectivity}

In order of importance, the abundance of Simuliidae, Hydrophilidae, Hydropsychidae, Heptageniidae, Planorbidae, Caenidae and Gerridae were the subset of macroinvertebrate families that best predicted flow connectivity in the taxonomy-based RF model (Fig. 6). In the case of biological traits, the proportion of filter feeders, organisms feeding on detritus $<$ $1 \mathrm{~mm}$, temporarily attached to the substrate, fliers, with a mean body size between 1 and $2 \mathrm{~cm}$, feeding on dead animals $\geq 1 \mathrm{~mm}$, with diapause and adult (imago) aquatic stages were prioritized as primary predictors in the trait-based RF model (Fig. 7). Other trait categories $a$ priori expected to be potential predictors of flow connectivity were not selected by the model. 
Ctree results for each of the biological predictors selected by RF showed that not all the macroinvertebrate families and not all biological trait categories selected by RF models created splits to classify flow connectivity. Within this group were the abundance of Caenidae family and the trait categories corresponding to organisms with a mean body size between 1 and $2 \mathrm{~cm}$, with diapause and adult (imago) aquatic stages, which were excluded for the subsequent analyses. Nevertheless, most of the taxonomical and biological predictors selected by RF classified flow connectivity into F or DP. For example, higher abundances of Hydrophilidae and Planorbiidae were more likely to be found in DP, with thresholds of 3.305 and $1.92 \log +1$ (ind $\mathrm{m}^{-2}$ ), respectively, together with the presence of Gerridae. In contrast, higher abundances of Simuliidae, with a threshold of $0.588 \log +1$ (ind $\mathrm{m}^{-2}$ ), and the presence of Hydropsychidae and Heptageniidae were more representative of F (Fig. 8). As expected from our a priori predictions (Table 3), higher proportions of macroinvertebrates feeding on detritus $<1 \mathrm{~mm}$, filter feeders, temporarily attached to the substrate were more likely to be present in F, with thresholds of $16.7 \%, 7.2 \%$, and $6.6 \%$, respectively (Fig. 9). Also in agreement with our a priori predictions, higher proportions of macroinvertebrates feeding on dead animals $\geq 1 \mathrm{~mm}$ and fliers occurred in DP, with thresholds of $2.6 \%$ and $3.5 \%$, respectively (Fig. 9). Consequently, five biological predictors formed the potential metrics to classify flow connectivity. Additionally, based on the performance and sum of the most important trait categories which are Detritus $>1 \mathrm{~mm}$, Filter feeder and temporarily attached, a new multimetric index is presented and named hereafter as Metatrait.

In general, the assessments of flow connectivity were more accurate in the trait-based Ctree models compared to the taxonomy-based ones. Three of the 6 biological trait-based Ctree models presented a substantial performance $(\kappa=0.64-0.70)$, whereas the others were moderate $(\kappa=0.58-0.59)$. Within these, the most accurate Ctree model corresponded to detritus $>1 \mathrm{~mm}(\kappa=0.7)$ and the Metatrait multimetric index $(\kappa=0.67)$, both with $88.6 \%$ overall accuracy (Table 4). Within the taxonomy-based metrics, only the Ctree based on the LIFE-F index presented a substantial performance $(\kappa=0.61)$, whereas others performed moderately $(\kappa=0.40-0.59)$ or badly $(\kappa=0)$. Metrics with $\kappa=0$ (i.e. Heptageniidae abundances) were not considered for validation (see methods). The Ctree performed on the $\mathrm{EPT} /(\mathrm{EPT}+\mathrm{OCH})$ ratio did not create any split to classify flow connectivity and, therefore, was not included in Table 4. 


\section{Validation}

Only the metrics and thresholds that effectively classified into F or DP were calculated for the external data from other reference streams. When validating these metrics, the highest classification success of flow connectivity was obtained for the abundance of Hydrophilidae and the Metatrait multimetric index, respectively with $83.5 \%$ and $82.1 \%$ of correct classifications (Table 4). However, the classification success predicted with the abundance of Hydrophilidae was much higher for F (91.7 \%) than for DP (20\%). In contrast, within the taxonomy metrics, Simuliidae abundance and the LIFE-F index, performed similarly when classifying DP and F, with correct classifications for both groups around $80 \%$. Within the trait-based metrics, metrics such as organisms that feed on detritus $>1 \mathrm{~mm}$ and filter feeders followed the same pattern when classifying DP and F. The lowest classification success was obtained for organisms feeding on dead animals of $>1 \mathrm{~mm}$ and Gerridae abundance, classifying $40.8 \%$ and $47.2 \%$ of stream reaches correctly, respectively.

\section{Discussion}

Macroinvertebrate families and traits as predictors of flow connectivity

The macroinvertebrate families that best predicted flow connectivity in this study agreed with their classification into rheophilic or limnephilic organisms (see Tachet et al., 2010; Mérigoux \& Dolédec, 2004; Cid, 2010) and demonstrated a distinct shift of dominant taxa from F (i.e. Hydropsychidae, Simuliidae, and Heptageniidae) to DP (i.e Hydrophilidae, Planorbidae, Gerridae). Hydrophilids are typically from lentic habitats and were the most important macroinvertebrate family in predicting flow connectivity. These beetles are well adapted to temporary water bodies and have wide distributional ranges (Ribera, 2000). They are also amongst the best indicators of pool habitats in temporary streams not only from the Mediterranean Basin (García-Roger et al., 2011) but also in temporary montane desert streams from Arizona (Bogan \& Lytle, 2007). The amphibious character of Hydrophilidae has been widely described, giving them the capacity to escape from pools when they completely dry out (Larned et al., 2010). While adults are herbivorous, the larvae are carnivorous and can also be cannibalistic, feeding almost on anything available as prey (Richmond, 1920). Other studies have shown that they can avoid oviposition when predatory 
fish are present in pools (Resetarits, 2001). Recently, Picazo, Millán \& Dolédec (2012) found that Hydrophilidae were the most diverse Coleoptera in terms of biological traits in Mediterranean freshwater ecosystems, confirming the high adaptation capacity of this family. Other lentic macroinvertebrates, such as Planorbidae (Gastropoda), were more abundant in DP, in agreement with the results in Bonada et al. (2006). Gastropoda were also more abundant in rewetted sediments from temporary streams compared to flowing streams in a study performed by Storey \& Quinn (2013). Reophilic taxa, such as Simuliidae, Hydropsychidae and Heptageniidae, were more abundant in F, as shown by other studies (Bonada et al., 2006; Bogan \& Lytle, 2007). However, within these reophilic families, Simuliidae was the best reophilic predictor of flow connectivity. Overall, our results complement the classical view that EPT and OCH taxa are the best indicators of flow connectivity (Bonada et al., 2006; Bonada et al., 2007a).

Of the five biological trait categories that best predicted flow connectivity, only two (i.e. organisms feeding on dead animals $\geq 1 \mathrm{~mm}$ and fliers) were associated to DP, while others were associated to $\mathrm{F}$ (i.e. organisms feeding on detritus $<1 \mathrm{~mm}$, filter feeders, and temporarily attached). As expected, macroinvertebrates temporarily attached to the substrate were very abundant in $\mathrm{F}$ as a result of morphological adaptation to flow (Statzner \& Bêche, 2010). The same was observed for the proportion of filter feeders (Lamouroux, Dolédec \& Gayraud, 2004; Mérigoux \& Dolédec, 2004), which could be related with the increased abundances of reophilic families, such as Hydropsychidae and Simuliidae. In general, biological traits provide a mechanistic response to direct stressors related with water discharge (e.g. near bottom flow), whereas indirect flow effects such as temporality may produce more diverse and equivocal responses (Statzner \& Bêche, 2010). As expected, those biological trait categories from our a priori hypotheses that are strictly linked to the action of flow were the best predictors of flow connectivity. This suggests that the observed shifts in the macroinvertebrate community are due to the selective loss of taxa susceptible to drying rather than selection for desiccation-resistant specialists, in agreement with other studies (Arscot et al., 2010; Datry, 2012; Vidal-Abarca et al., 2013). However, other trait categories may become more important as a result of opportunism. For instance, the higher proportion of macroinvertebrates feeding on dead animals found in DP could be related with an increased mortality during drought (Ledger et al., 2011). On the other hand, the higher proportion of fliers in DP suggests that aquatic invertebrates inhabiting temporary streams also have avoidance strategies to escape immediately to neighbouring water bodies (Bonada 
$\&$ Resh, 2013). The fact that other a priori predicted traits (e.g. life history traits) were not linked to flow connectivity could be explained by the Mediterranean behaviour of all these streams as a result of filters acting at larger spatial and temporal scales (Bonada et al., 2007a, 2007b).

Predicting flow connectivity using biological metrics: Bio-AS Tool

The selected metrics and thresholds proposed in this study were able to successfully classify flow connectivity in most of the reference temporary streams analysed. This provides a potential new method to determine flow connectivity at the reach scale that can be particularly relevant when hydrological data are missing and the AS-Tool developed under the MIRAGE project cannot be applied. Even when gauging stations are present, they may under-represent temporary river segments (Snelder et al., 2013) or provide stream flow statistics that could be a poor surrogate for ecologically significant reach-scale hydraulic metrics (Turner \& Stewardson, 2014). Therefore, the combination of metrics proposed by the BioAS-Tool can be an alternative method for predicting hydrological conditions of an temporary stream reach (e.g. AS-Tool, see Prat et al., 2014), thereby becoming another important element of the integrated assessment for temporary streams provided by the MIRAGE Toolbox (Prat et al., 2014). In order to exemplify the application of the BioASTool in ecological status assessments, we used a subset of the validation samples from one temporary reference stream taken in different seasons (spring and summer during 10 years) from which data on IBMWP index (Iberian Biological Monitoring Working Party, AlbaTercedor et al., 2004) was available. The IBMWP index is commonly used for water quality bioassessment in rivers from the Mediterranean Basin (Munné \& Prat, 2009). On the one hand, these samples were classified as F or DP by direct field observations, and on the other hand, the same classification was used using the BioAS-Tool. The highest variability of IBMWP is displayed in the DP classification with direct field observation (Fig. 10a), and corroborates the difficulty of evaluating antecedent flow conditions in DP. In contrast, the variability of the IBMWP index for the same samples was reduced when F or DP was classified using the Metatrait multimetric index (Fig. 10b). Those samples presenting higher IBMWP values would have a macroinvertebrate community typical of $F$ according to the BioAS-Tool, although DP was registered at the moment of sampling. Therefore, the aquatic community may be more representative of antecedent conditions than conditions present at the time the sample was collected. This can occur when sampling takes place just after the 
fracture into several pools and the probability of finding predictors of $\mathrm{F}$ can be still high before the succession to a pool-dominated community takes place. In this sense, the classification of DP or F by direct observation in the field could be biased to any side whereas precision increases using the BioAS-Tool. This can be very relevant when setting reference conditions in temporary rivers. For instance, Sánchez-Montoya et al. (2009) were not able to validate the reference condition criteria using biological communities from temporary streams due to the high variability of reference values of biological indices. When only spring samples were used to establish reference conditions to minimize the effect of summer drought, a high variability was also observed depending on the index used (SánchezMontoya et al., 2010; Munné \& Prat, 2011). Therefore, rather than seasonality, between-site variability attributed to different frequencies and durations of connections and disconnections is indeed a key aspect to be considered (Larned et al., 2010). In this sense, the BioAS-tool can contribute to predict hydrologic conditions independently of the season, and, for instance, be applied in those samples taken in the past and used for setting reference conditions.

Although the methods used in this study offer robust and accurate classifications (Cutler et al., 2007), several limitations were identified. Firstly, different percentages of DP correctly classified compared to $F$ were observed for the different metrics, which could be associated to a high variability of ecological responses in each pool. For instance, the presence of riparian forest could buffer temperature increase through its shading effect (Beschta, 1997; Kristensen et al., 2013) and contribute toward maintaining the level of dissolved oxygen in the pool. Similar effects could be observed if the pool is connected to the groundwater. In contrast, if the pool remains exposed to direct solar irradiation the contraction process goes faster (Lake, 2011). Depending on the time elapsed since disconnection took place, different environmental conditions may exert greater or lesser effects on biological communities because of changes in water quality (Lake, 2011), available mesohabitats and microhabitats (García-Roger et al., 2011, 2013), and biological interactions (Acuña et al., 2005). Secondly, the imbalance between the number of stream reaches in DP $(\mathrm{n}=8)$ and $\mathrm{F}(\mathrm{n}=27)$ in the training dataset could have caused some level of bias in the classification, under-predicting the minority class (Evans et al., 2009). Still, the classification performance using most of the trait-based metrics was higher compared to the taxonomybased metrics. Therefore, a taxonomy-based approach could be limiting when large spatial scales are compared due to the influence of historical or phylogenetic factors (Bonada et al., 2008), whereas traits may be less affected (Bonada et al., 2007b). 
The Mediterranean Basin is considered a hotspot of biodiversity with high rates of endemism (Myers et al., 2000; Bonada \& Resh, 2013) but also with highly threatened biota (Filipe et al., 2013). Studies analysing climate change effects on the distribution of freshwater organisms and biodiversity have shown that southern European regions will be the most affected (Domish et al., 2013; Markovick et al., 2014). In this context, given that long-term datasets on macroinvertebrates can be obtained from biomonitoring programmes usually identified at the family level, the BioAs-Tool could provide a site-specific history in flow connectivity by using samples collected in the past and contribute toward assessing temporal and spatial climate change effects in reference streams from the Mediterranean Basin.

This study is the first in providing a methodological framework for predicting aquatic states using both taxonomic and biological trait composition of macroinvertebrate communities from temporary streams. Although further development is needed, identifying the relevant metrics responding to flow cessation and their thresholds at the reach scale is of particular interest for monitoring, restoration and conservation purposes, especially knowing that the absence of hydrological data is a common problem in Mediterranean temporary rivers. This represents an important step towards an adequate management of rivers in the Mediterranean Basin as well as towards increasing their recognition in policies related to water and biodiversity.

\section{Future perspectives}

Changes in biotic communities with increasing flow intermittence are generally gradual, with no clearly defined thresholds (Datry et al., 2014). Due to the management focus of our study, we defined thresholds of flow discharge (F and DP) and obtained the response of particular macroinvertebrate groups and biological traits. However, a detailed analysis of the gradual changes of biotic communities along the different hydrological conditions that the river ecosystem undergoes (from a flood state to complete drying) would be needed. This would allow the development of more precise tools needed to predict past and future hydrological conditions using biological data and advance in the science of temporary rivers.

\section{Acknowledgements}


This study has been supported by the European Union Project MIRAGE FP7-ENV-2007-1 (Mediterranean Intermittent River MAnaGEment) from the specific programme 'Cooperation', theme 'Environment (including Climate Change)' under its 7th Research Framework Programme. We thank Pau Fortuño for his assistance in biological indices data calculations, Javier Martínez-López and Tano Gutiérrez for their help in RF analyses and Jérôme Latron for the hydrogram. We are very grateful to the reviewer's comments, which notably improved the quality of this work.

\section{References}

Acuña V, Muñoz I, Giorgi A, Omella M, Sabater F, Sabater S. Drought and postdrought recovery cycles in an intermittent Mediterranean stream: structural and functional aspects. J North Am Benthol Soc 2005;24:919-933.

Acuña V, Datry T, Marshall J, Barceló D, Dahm CN, Ginebreda A, et al. Why should we care about temporary waterways? Science 2014;343:1080-1081.

Alba-Tercedor J, Jáimez-Cuéllar P, Alvarez M, Avilés J, Bonada N, Casas J, et al. Caracterización del estado ecológico de los ríos mediterráneos ibéricos mediante el índice IBMWP (antes BMWP'). Limnetica 2004;21:175-185.

Arscott DB, Larned S, Scarsbrook MR, Lambert P. Aquatic invertebrate community structure along an intermittence gradient: Selwyn River, New Zealand. J North Am Benthol Soc 2010;29:530-545.

Arscott DB, Larned S, Scarsbrook MR, Lambert P. Aquatic invertebrate community structure along an intermittence gradient: Selwyn River, New Zealand. J North Am Benthol Soc 2010;29:530-545.

Bêche LA, Resh VH Short-term climatic trends affect the temporal variability of macroinvertebrates in California 'Mediterranean' streams. Freshw Biol 2007;52:2317-2339.

Beschta RL. Riparian shade and stream temperature: an alternative perspective. Rangelands 1997;19:25-28.

Bogan MT, Lytle D. Seasonal flow variation allows "time-sharing" by disparate aquatic insect communities in montane desert streams. Freshw Biol 2007;52:290-304.

Bonada N, Rieradevall M, Prat N, Resh VH. Benthic macroinvertebrate assemblages and macrohabitat connectivity in Mediterranean-climate streams of northern California. J North Am Benthol Soc 2006;25:32-43. 
Bonada N, Rieradevall M, Prat N. Macroinvertebrate community structure and biological traits related to flow permanence in a Mediterranean river network. Hydrobiologia 2007a;589:91-106.

Bonada N, Dolédec S, Statzner B. Taxonomic and biological trait differences of stream macroinvertebrate communities between mediterranean and temperate regions: implications for future climatic scenarios. Glob Change Biol 2007b;13:1658-1671.

Bonada N, Rieradevall M, Dallas H, Davis J, Day J, Figueroa R, et al. Multi-scale assessment of macroinvertebrate richness and composition in Mediterranean-climate rivers. Freshw Biol 2008;53:772-788.

Bonada N, Resh VH. Mediterranean-climate streams and rivers: geographically separated but ecologically comparable freshwater systems. Hydrobiologia 2013;719:1-29.

Boulton AJ. Parallels and contrasts in the effects of drought on stream macroinvertebrate assemblages. Freshw Biol 2003;48:1173-1185.

Boulton AJ, Lake PS. Effects of drought on stream insects and its ecological consequences. In: Lancaster J, Briers RA Briers, editors. Aquatic insects: challenges to populations. Proceedings of the Royal entomological Society's $24^{\text {th }}$ symposium, CAB International; 2008. p. 81-102.

Breiman L. Random Forests. Mach Learn 2001;45:5-32.

Buffagni A, Armanini DG, Erba S. Does the lentic-lotic character of rivers affect invertebrate metrics used in the assessment of ecological quality? J Limnol 2009;68:92-105.

Buffagni A, Erba S, Armanini DG. The lentic-lotic character of Mediterranean rivers and its importance to aquatic invertebrate communities. Aquat Sci 2010;72:45-60.

Cid N. Ecology of he benthic macroinvertebrates in the lower Ebro River, community characterization, population dynamics and bioaccumulation of pollutants in response to environmental factors. PhD Thesis. University of Barcelona, Catalonia; 2010.

Champely S, Chessel D. Measuring biological diversity using Euclidean metrics. Environ Ecol Stat 2002;9:167-177.

Chessman B. Relationships between lotic macroinvertebrate traits and responses to extreme drought. Freshw Biol 2015;60:50-63.

Chevenet F, Dolédec S, Chessel D. A fuzzy coding approach for the analysis of long-term ecological data. Freshw Biol 1994;31:295-310.

Clarke A, Mac Nally R, Bond N, Lake PS. Flow permanence affects aquatic macroinvertebrate diversity and community structure in three headwater streams in a forested catchment. Can J Fish Aquat Sci 2010;67:1649-1657.

Cutler DR, Edwards TC, Beard KH, Cutler A, Hess KT, Gibson J, et al. Random forests for classification in ecology. Ecology 2007;88:2783-92. 
Datry T. Benthic and hyporheic invertebrate assemblages along a flow intermittence gradient: effects of duration of dry events. Freshw Biol 2012;57:563-574.

Datry T, Larned ST, Fritz KM, Bogan MT, Wood PJ, Meyer EI, et al. Broad-scale patterns of invertebrate richness and community composition in temporary rivers: effects of flow intermittence. Ecography 2014a;37:94-104.

Datry T, Larned ST, Tockner K. Intermittent Rivers: A Challenge for Freshwater Ecology. BioScience 2014b;64:229-235.

Dolédec S, Olivier JM, Statzner B. Accurate description of the abundance of taxa and their biological traits in stream invertebrate communities: effects of taxonomic and spatial resolution. Arch Hydrobiol 2000;148:25-43.

Domisch S, Araújo MB, Bonada N, Pauls SU, Jähnig SC, Haase P. Modelling distribution in European stream macroinvertebrates under future climates. Glob Change Biol 2013;19:752-62.

Dray S, Dufour AB. The ade4 package: implementing the duality diagram for ecologists. J Stat Softw 2007;22:1-20.

Dunbar MJ, Pedersen ML, Cadman D, Extence C, Waddingham J, Chadd R, Larsen SE. River discharge and local scale physical habitat influence macroinvertebrate LIFE scores. Freshw Biol 2010;55:226-242.

EC (European Commission). River basin management in a changing climate. Common Implementation Strategy for the Water Framework Directive Guidance document number 24; 2009.

Evans JS, Cushman SA. Gradient modelling of conifer species using random forests. Landscape Ecol 2009;24:673-683.

Extence C, Balbi D, Chadd R. River flow indexing using British benthic macroinvertebrates: a framework for setting hydroecological objectives. Regul River 1999;15:545-574.

Filipe A, Lawrence J, Bonada N. Vulnerability of stream biota to climate change in mediterranean climate regions: a synthesis of ecological responses and conservation challenges. Hydrobiologia 2013;719:331-351.

Forzieri G, Feyen L, Rojas R, Flörke M, Wimmer F, Bianchi A. Ensemble projections of future streamflow droughts in Europe. Hydrol Earth Syst Sc 2014;18:85-108.

Fritz KM, Johnson BR, Walters DM. Field Operations Manual for Assessing the Hydrologic Permanence and Ecological Condition of Headwater Streams. EPA/600/ R-06/126 2006 (last access: 16 October 2014). Washington DC: US Environmental Protection Agency, Office of Research and Development, available at: http://www.epa.gov/eerd/methods/headwater.html.

Fritz KM, Johnson BR, Walters DM. Environmental indicators of hydrologic permanence in forested headwater streams. J North Am Benthol Soc 2008;27:690-704. 
Gallart F, Prat N, García-Roger EM, Latron J, Rieradevall M, Llorens P, et al. A novel approach to analysing the regimes of temporary streams in relation to their controls on the composition and structure of aquatic biota. Hydrol Earth Syst Sc 2012;16:31653182 .

García-Roger EM, Mar Sánchez-Montoya M, Gómez R, Suárez ML, Vidal-Abarca MR, Latron J, et al. Do seasonal changes in habitat features influence aquatic macroinvertebrate assemblages in perennial versus temporary Mediterranean streams? Aquat Sci 2011;73:567-579.

García-Roger EM, Sánchez-Montoya MM, Cid N, Erba S, Karaouzas I, Verkaik I, et al. Spatial scale effects on taxonomic and biological trait diversity of aquatic macroinvertebrates in Mediterranean streams. Fund Appl Limnol 2013;183:89-105.

Gayraud S, Statzner B, Bady P, Haybachp A, Schöll F, Usseglio-Polatera P, et al. Invertebrate traits for the biomonitoring of large European rivers: an initial assessment of alternative metrics. Freshw Biol 2003;48:2045-2064.

De Girolamo AM, Lo Porto A, Pappagallo G, Tzoraki O, Gallart F. The hydrological status concept: application at a temporary river (Candelaro, Italy). River Res Appl 2014; doi: $10.1002 /$ rra.2786

Gore JA, Layzer JB, Mead J. Macroinvertebrate instream flow studies after 20 years: A role in stream management and restoration. Regul River 2001;17:527-542.

Hothorn T., Hornik K., Strobl C. \& Zeileis A. Party: A Laboratory for Recursive Part(y)itioning. R package; 2014.

Illies J. Limnofauna europaea. G. Fischer Verlag: Amsterdam; 1978.

Kristensen PB, Kristensen EA, Riis T, Baisner AJ, Larsen SE, Verdonschot PFM, et al. Riparian forest as a management tool for moderating future thermal conditions of lowland temperate streams. Hydrol Earth Syst Sc 2013;10:6081-6106.

Lake PS. Ecological effects of perturbation by drought in flowing waters. Freshw Biol 2003;48:1161-1172.

Lake PS. Drought and Aquatic Ecosystems: Effects and Responses. Chichester: John Wiley \& Sons; 2011.

Lamouroux N, Dolédec S, Gayraud S. Biological traits of stream macroinvertebrate communities: effects of microhabitat, reach, and basin filters. J North Am Benthol Soc 2004;23:449-466.

Larned ST, Datry T, Arscott DB, Tockner K. Emerging concepts in temporary-river ecology. Freshw Biol 2010;55:717-738.

Ledger ME, Edwards FK, Brown LE, Milner AM, Woodward G. Impact of simulated drought on ecosystem biomass production: an experimental test in stream mesocosms. Glob Change Biol 2011;17:2288-2297. 
Liaw A, Wiener M. Classification and Regression by randomForest. R News 2002;2: 18-22.

Logez M, Pont D. Global warming and potential shift in reference conditions: the case of functional fish-based metrics. Hydrobiologia 2012;704:417-436.

Manel S, Williams HC, Ormerod SJ. Evaluating presence-absence models in ecology: the need to account for prevalence. J Appl Ecol 2001;38:921-931.

Markovic D, Carrizo D, Freyhof J, Cid N, Szabolcs L, Scholz M, et al. Europe's freshwater biodiversity under climate change: distribution shifts and conservation needs. Divers Distrib 2014;20:1097-1107.

Mellado-Díaz AM, Suárez-Alonso ML, Vidal-Abarca MR. Biological traits of stream macroinvertebrates from a semi-arid catchment: patterns along complex environmental gradients. Freshw Biol 2008;53:1-21.

Mérigoux S, Dolédec S. Hydraulic requirements of stream communities: a case study on invertebrates. Freshw Biol 2004;49:600-613.

Mérigoux S, Lamouroux N, Olivier JM, Dolédec S. (2009) Invertebrate hydraulic preferences and predicted impacts of changes in discharge in a large river. Freshw Biol 2009;54:1343-1356.

Meyer D, Zeileis A, Hornik K. vcd: Visualizing Categorical Data. R package version 1.3-1; 2013.

Munné A, Prat N. Use of macroinvertebrate-based multimetric indices for water quality evaluation in Spanish Mediterranean rivers: an intercalibration approach with the IBMWP index. Hydrobiologia 2009;628:203-225.

Munné A, Prat N. Effects of Mediterranean climate annual variability on stream biological quality assessment using macroinvertebrate communities. Ecol Indic 2011;11:651662 .

Myers N, Mittermeier RA, Mittermeier CG, da Fonseca GAB, Kent J. Biodiversity hotspots for conservation priorities. Nature 2000;403:853-858.

Oksanen J, Blanchet FG, Kindt R, Legendre P, O'Hara RG Simpson GL, et al. vegan: Community Ecology Package. R package version 2.0-9. http://CRAN.Rproject.org/package=vegan; 2014 .

Nikolaidis NP, Demetropoulou L, Froebrich J, Jacobs C, Gallart F, Prat N, et al. Towards sustainable management of Mediterranean river basins: policy recommendations on management aspects of temporary streams. Water Policy 2013;15:830-849.

Pace G, Bonada N, Prat N. Long-term effects of climatic-hydrological drivers on macroinvertebrate richness and composition in two Mediterranean streams. Freshw Biol 2013;58:1313-1328. 
Picazo F, Millán A, Dolédec S. Are patterns in the taxonomic, biological and ecological traits of water beetles congruent in Mediterranean ecosystems? Freshw Biol 2012;57:21922210.

Prat N, Gallart F, Von Schiller D, Polesello S, García-Roger EM, Latron J, et al. The Mirage Toolbox: an Integrated Assessment Tool for Temporary Streams. River Res Appl 2014;30:1318-1334.

R Core Team. R: A language and environment for statistical computing. R Foundation for Statistical Computing, Vienna, Austria. URL http://www.R-project.org/; 2013.

Resetarits W. Colonization under threat of predation: avoidance of fish by an aquatic beetle, Tropisternus lateralis (Coleoptera: Hydrophilidae). Oecologia 2001;129:155-160.

Ribera I. Biogeography and conservation of Iberian water beetles. Biol Conserv 2000;92:131-150.

Richmond EA. Studies on the biology of the aquatic Hydrophilidae. B Am Mus Nat Hist 1920;42:1-94.

Robson BJ, Chester ET, Austin CM. Why life history information matters: drought refuges and macroinvertebrate persistence in non-perennial streams subject to a drier climate. Mar Freshwater Res 2011;62:801-810.

Schneider C, Laizé CLR, Acreman MC, Flörke M. How will climate change modify river flow regimes in Europe? Hydrol Earth Syst Sc 2013;17:325-339.

Sheldon F. Incorporating Natural Variability into the Assessment of Ecological Health in Australian Dryland Rivers. Hydrobiologia 2005;552:45-56.

Sánchez-Montoya MM, Vidal-Abarca MR, Puntí T, Poquet JM, Prat N, Rieradevall M, et al. Defining criteria to select reference sites in Mediterranean streams. Hydrobiologia 2009;619:39-54.

Sánchez-Montoya MM, Vidal-Abarca MR, Suárez ML. Comparing the sensitivity of diverse macroinvertebrate metrics to a multiple stressor gradient in Mediterranean streams and its influence on the assessment of ecological status. Ecol Indic 2010;10:896-904.

Sánchez-Montoya MDM, Arce MI, Vidal-Abarca MR, Suárez ML, Prat N, Gómez R. Establishing physico-chemical reference conditions in Mediterranean streams according to the European Water Framework Directive. Water Res 2012;46:2257-69.

Snelder TH, Datry T, Lamouroux N, Larned ST, Sauquet E, Pella H, et al. Regionalization of patterns of flow intermittence from gauging station records. Hydrol Earth Syst Sc 2013;17:2685-2699.

Statzner B, Bêche LA. Can biological invertebrate traits resolve effects of multiple stressors on running water ecosystems? Freshw Biol 2010;55:80-119. 
Statzner B, Bis B, Dolédec S, Usseglio-Polatera P. Perspectives for biomonitoring at large spatial scales: a unified measure for the functional composition of invertebrate communities in European running waters. Basic Appl Ecol 2001;2:73-85.

Storey RG, Quinn JM. Survival of aquatic invertebrates in dry bed sediments of intermittent streams: temperature tolerances and implications for riparian management. Freshw Sci 2013;32:250-266.

Strobl C, Hothorn T, Zeileis A. Party on! R Journal 2009;1:14-17.

Suren AM, Jowett IG. Effects of floods versus low flows on invertebrates in a New Zealand gravel-bed river. Freshw Biol 2006;51:2207-2227.

Tachet H, Richoux P, Bournard M, Usseglio-Polatera P. Invertébrés d'eau douce: systématique, biologie, écologie. Paris: CNRS Éditions; 2010.

Turner M, Stewardson M. Hydrologic indicators of hydraulic conditions that drive flow-biota relationships. Hydrolog Sci J 2014;59:659-672.

Vidal-Abarca MR, Sánchez-Montoya MM, Guerrero C, Gómez R, Arce MI, García-García $\mathrm{V}$., et al. Effects of intermittent stream flow on macroinvertebrate community composition and biological traits in a naturally saline Mediterranean stream. J Arid Environ 2013;99:28-40.

Wilby RL, Orr H, Watts G, Battarbee RW, Berry PM, Chadd R, et al. Evidence needed to manage freshwater ecosystems in a changing climate: Turning adaptation principles into practice. Sci Total Enviro 2010;408:4150-4164.

Williams DD. Environmental constraints in temporary fresh waters and their consequences for the insect fauna. J North Am Benthol Soc 1996;15:634-650.

Williams DD. The biology of temporary waters. New York: Oxford University Press; 2006. 


\section{Tables}

Table 1. Summary of location, climate, flow connectivity and invertebrate sampling dates of the temporary streams used in this study $(\mathrm{n}=35)$. F, flowing; DP, disconnected pools.

\begin{tabular}{|c|c|c|c|c|c|c|c|}
\hline Country & State/Region & Stream & Reach & Year & Season & $\begin{array}{l}\text { Flow } \\
\text { connectivity }\end{array}$ & $\begin{array}{l}\text { Discharge } \\
\left(1 \cdot \mathrm{s}^{-1}\right)\end{array}$ \\
\hline \multirow[t]{4}{*}{ France } & $\begin{array}{l}\text { Languedoc- } \\
\text { Roussillon }\end{array}$ & Vêne & Issanka & 2010 & Spring & $\mathrm{F}$ & 495 \\
\hline & & & & 2010 & Summer & $\mathrm{F}$ & 83 \\
\hline & & & Montbazin K & 2010 & Spring & $\mathrm{F}$ & 187 \\
\hline & & & Montbazin R & 2010 & Summer & DP & 0.00 \\
\hline \multirow[t]{8}{*}{ Greece } & Laconia & Evrotas & Kolliniatiko & 2010 & Spring & $\mathrm{F}$ & 239 \\
\hline & & & & 2010 & Summer & $\mathrm{F}$ & 22 \\
\hline & & & & 2010 & Autumn & $\mathrm{F}$ & 46 \\
\hline & & & Rasina & 2010 & Spring & $\mathrm{F}$ & 2873 \\
\hline & & & Sentenikos & 2010 & Spring & $\mathrm{F}$ & 1035 \\
\hline & & & & 2010 & Summer & $\mathrm{DP}$ & 0.00 \\
\hline & & & & 2010 & Autumn & DP & 0.00 \\
\hline & & & & 2011 & Winter & $\mathrm{F}$ & 214 \\
\hline \multirow[t]{5}{*}{ Italy } & Molise & Biferno & Riomaio & 2010 & Spring & $\mathrm{F}$ & 55 \\
\hline & & & & 2010 & Summer & DP & 0.35 \\
\hline & Puglia & Candelaro & Celone & 2010 & Spring & $\mathrm{F}$ & 132 \\
\hline & & & & 2010 & Summer & $\mathrm{F}$ & 26 \\
\hline & & & FM & 2010 & Spring & $\mathrm{F}$ & 17 \\
\hline \multirow[t]{2}{*}{ Portugal } & Alentejo & Enxöe & Vale do Bargo E & 2010 & Spring & $\bar{F}$ & 49 \\
\hline & & & & 2010 & Summer & DP & 0.00 \\
\hline \multirow[t]{16}{*}{ Spain } & Catalonia & Vallcebre & Cal Rodó & 2009 & Spring & $\mathrm{F}$ & 118 \\
\hline & & & & 2009 & Summer & $\mathrm{F}$ & 12 \\
\hline & & & & 2010 & Spring & $\mathrm{F}$ & 57 \\
\hline & & & & 2010 & Summer & $\mathrm{F}$ & 33 \\
\hline & & & Can Vila & 2009 & Spring & $\mathrm{F}$ & 29 \\
\hline & & & & 2009 & Summer & $\mathrm{DP}$ & 0.0 \\
\hline & & & & 2010 & Spring & $\mathrm{F}$ & 16 \\
\hline & & & & 2010 & Summer & $\mathrm{F}$ & 4 \\
\hline & Murcia & Taibilla & Blanco & 2009 & Spring & $\mathrm{F}$ & 10 \\
\hline & & & & 2009 & Summer & $\mathrm{F}$ & 2 \\
\hline & & & & 2010 & Spring & $\mathrm{F}$ & 25 \\
\hline & & & & 2010 & Autumn & $\mathrm{F}$ & 13 \\
\hline & & & Rogativa & 2009 & Spring & $\mathrm{F}$ & 2 \\
\hline & & & & 2009 & Summer & DP & 0.08 \\
\hline & & & & 2010 & Spring & $\mathrm{F}$ & 11 \\
\hline & & & & 2010 & Autumn & $\mathrm{DP}$ & 0.07 \\
\hline
\end{tabular}


Table 2. Flow thresholds between aquatic states and $\mathrm{F}$ and DP in $1 \mathrm{~s}^{-1}$ defined in different stream reaches included in the present study (adapted from Gallart et al., 2012). F, flowing; DP, disconnected pools.

\begin{tabular}{llllll}
\hline Flow connectivity & Aquatic state & Stream reach & & \\
\cline { 2 - 5 } & & Vêne, Montbazin K & Candelaro, Celone & Vallcebre, Can Vila & Taibilla, Rogativa \\
\hline F & Hyperheic & $>800$ & $>1000$ & $>20$ & $>1000$ \\
& Eurheic & $100-800$ & $30-1000$ & $1-20$ & $10-1000$ \\
& Oligorheic & $50-100$ & $50-30$ & $0.35-1$ & $3-10$ \\
DP & Arheic & $10-50$ & $1-10$ & $0.05-0.35$ & $0.05-3$ \\
& Hyporheic & $<10$ & $<1$ & $<0.05$ & $<0.05$ \\
\hline
\end{tabular}

Table 3. Biological trait categories expected to predict flow connectivity and to be predominant in flow (F) and disconnected pools (DP). Rationale formulated after Wallace \& Webster (1996), Bonada et al. (2007) and Statzner \& Bêche (2010).

\begin{tabular}{|c|c|c|c|}
\hline Trait & Category & $\begin{array}{l}\text { Predicted } \\
\text { connectivity }\end{array}$ & Rationale \\
\hline \multirow[t]{5}{*}{ Maximal size } & $>0.5-1 \mathrm{~cm}$ & $\mathrm{~F}$ & $\begin{array}{l}\text { The presence of flow requires less resilience capacity and permits larger sizes, } \\
\text { but also constrains very large sizes, therefore favouring intermediate sizes in } \\
\text { flow conditions. }\end{array}$ \\
\hline & $>1-2 \mathrm{~cm}$ & $\mathrm{~F}$ & (As above) \\
\hline & $>2-4 \mathrm{~cm}$ & DP & $\begin{array}{l}\text { Very large sizes not adapted to high hydraulic stress are less constrained in } \\
\text { disconnected pools. }\end{array}$ \\
\hline & $>4-8 \mathrm{~cm}$ & DP & (As above) \\
\hline & $>8 \mathrm{~cm}$ & DP & (As above) \\
\hline Aquatic stages & Adult (imago) & DP & $\begin{array}{l}\text { Disconnected pools may act as refuge for many aquatic adults that cannot } \\
\text { escape by flying (e.g. Mollusca, Crustacea) thus their relative abundance could } \\
\text { be increased. }\end{array}$ \\
\hline \multirow[t]{2}{*}{ Dispersal } & Aquatic passive & $\mathrm{F}$ & Flow allows downstream drift. \\
\hline & Aerial active & DP & Flow cessation favours flying. \\
\hline Resistance forms & $\begin{array}{l}\text { Diapause or } \\
\text { dormancy }\end{array}$ & DP & $\begin{array}{l}\text { When flow is disconnected increased resistance against droughts may be } \\
\text { favoured. }\end{array}$ \\
\hline \multirow[t]{2}{*}{ Respiration } & Gills & $\mathrm{F}$ & Increased oxygen deficit in disconnected pools may limit aquatic respiration. \\
\hline & Spiracle (aerial) & DP & Increased oxygen deficit in disconnected pools may favour air breathers. \\
\hline \multirow{4}{*}{$\begin{array}{l}\text { Locomotion and } \\
\text { substrate relation }\end{array}$} & Flier & DP & When flow is disconnected, strategies to escape may be favoured. \\
\hline & Surface swimmer & DP & Release from action of flow in disconnected pools favours swimming. \\
\hline & Full water swimmer & DP & (As above) \\
\hline & $\begin{array}{l}\text { Temporarily } \\
\text { attached }\end{array}$ & $\mathrm{F}$ & $\begin{array}{l}\text { The action of flow favours organisms that have adaptations for attachment to } \\
\text { the substrate. }\end{array}$ \\
\hline \multirow[t]{2}{*}{ Food } & Detritus $<1 \mathrm{~mm}$ & $\mathrm{~F}$ & $\begin{array}{l}\text { Higher availability of suspended organic matter (i.e. FPOM) transported by } \\
\text { flow }\end{array}$ \\
\hline & $\begin{array}{l}\text { Dead animal }>1 \\
\mathrm{~mm}\end{array}$ & DP & $\begin{array}{l}\text { Increased number of dead organisms can be accumulated due to stress as pools } \\
\text { decline in water quality }\end{array}$ \\
\hline Feeding habits & Filter feeder & $\mathrm{F}$ & Higher availability of suspended organic matter under flow conditions \\
\hline
\end{tabular}




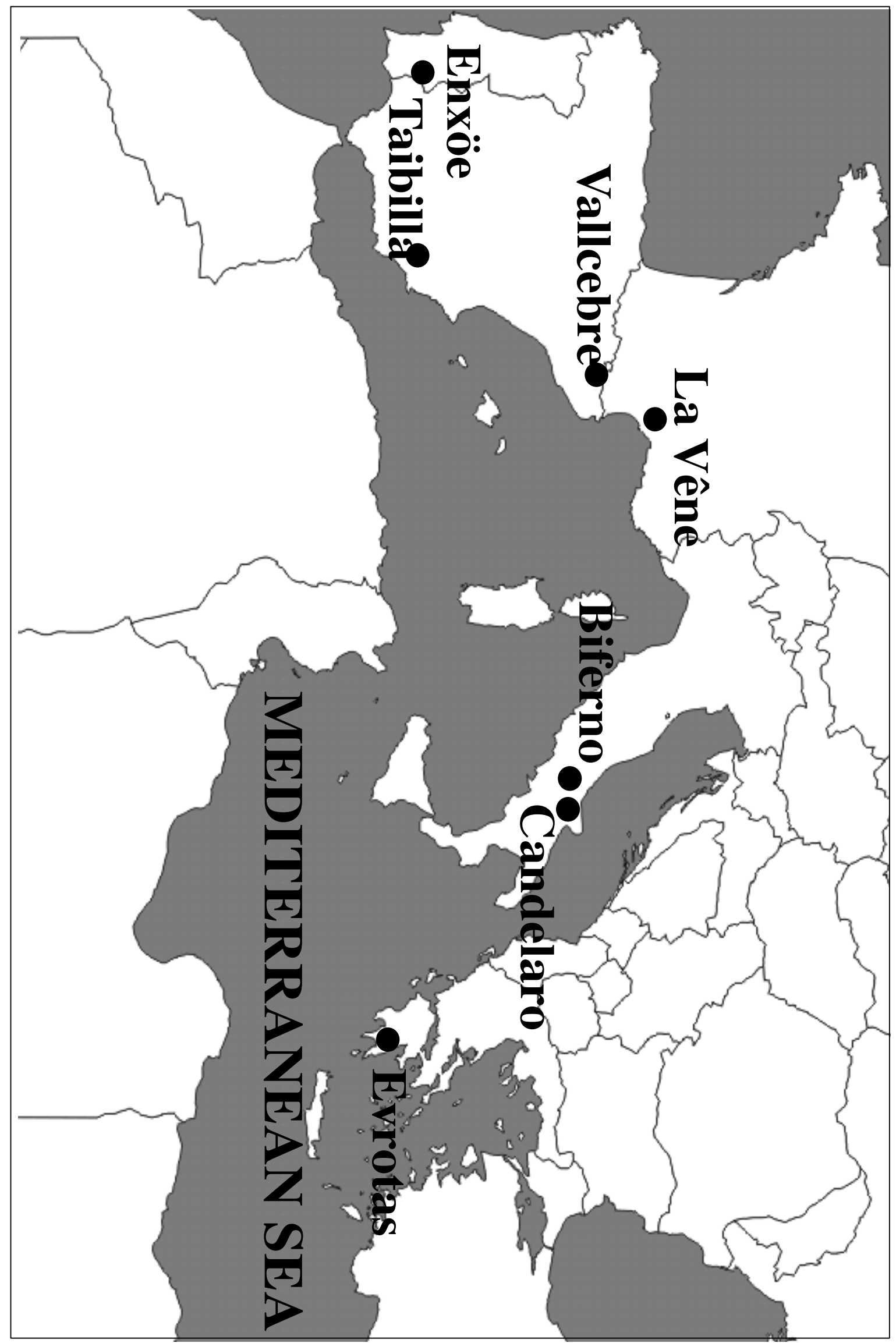




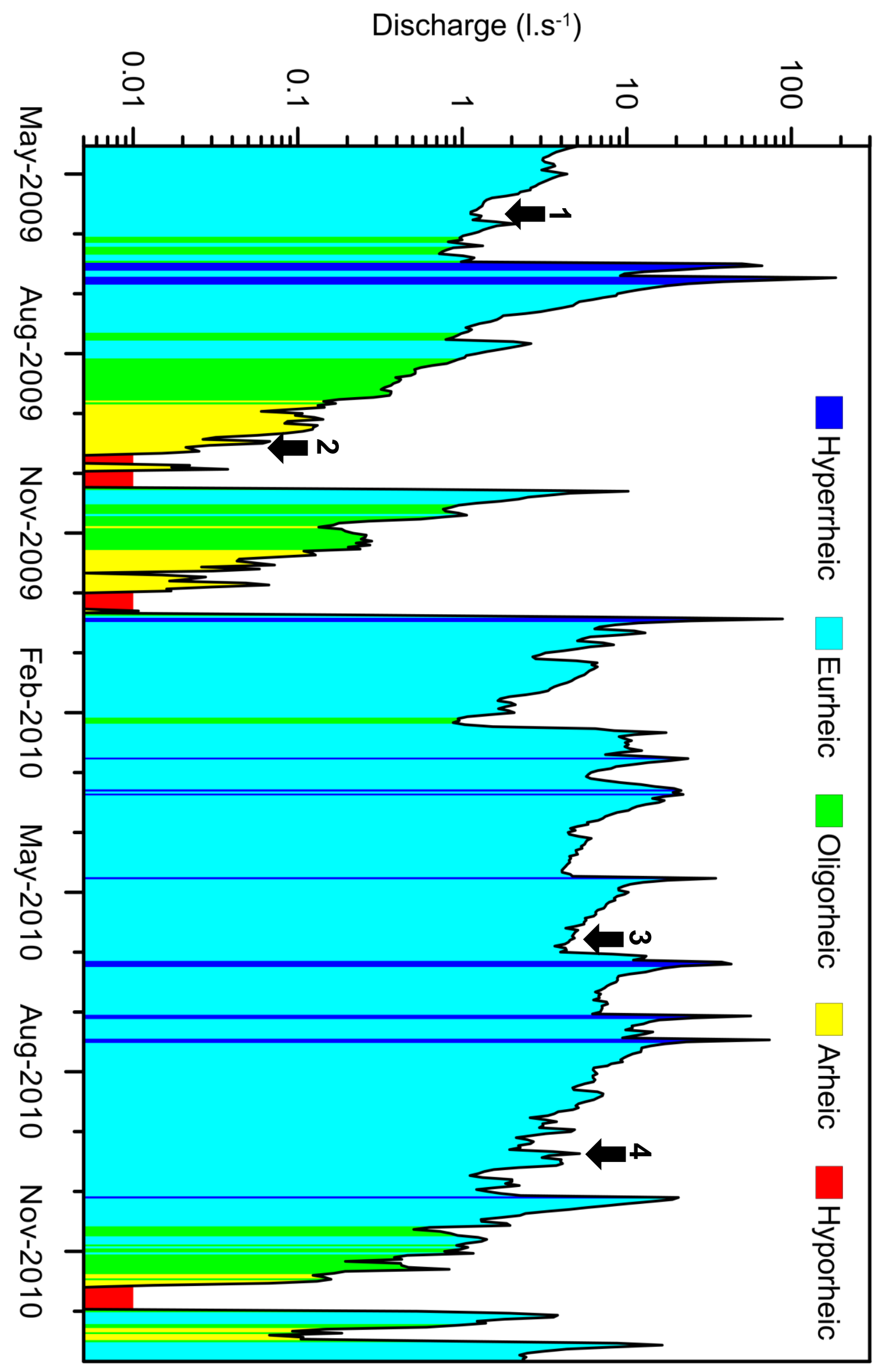




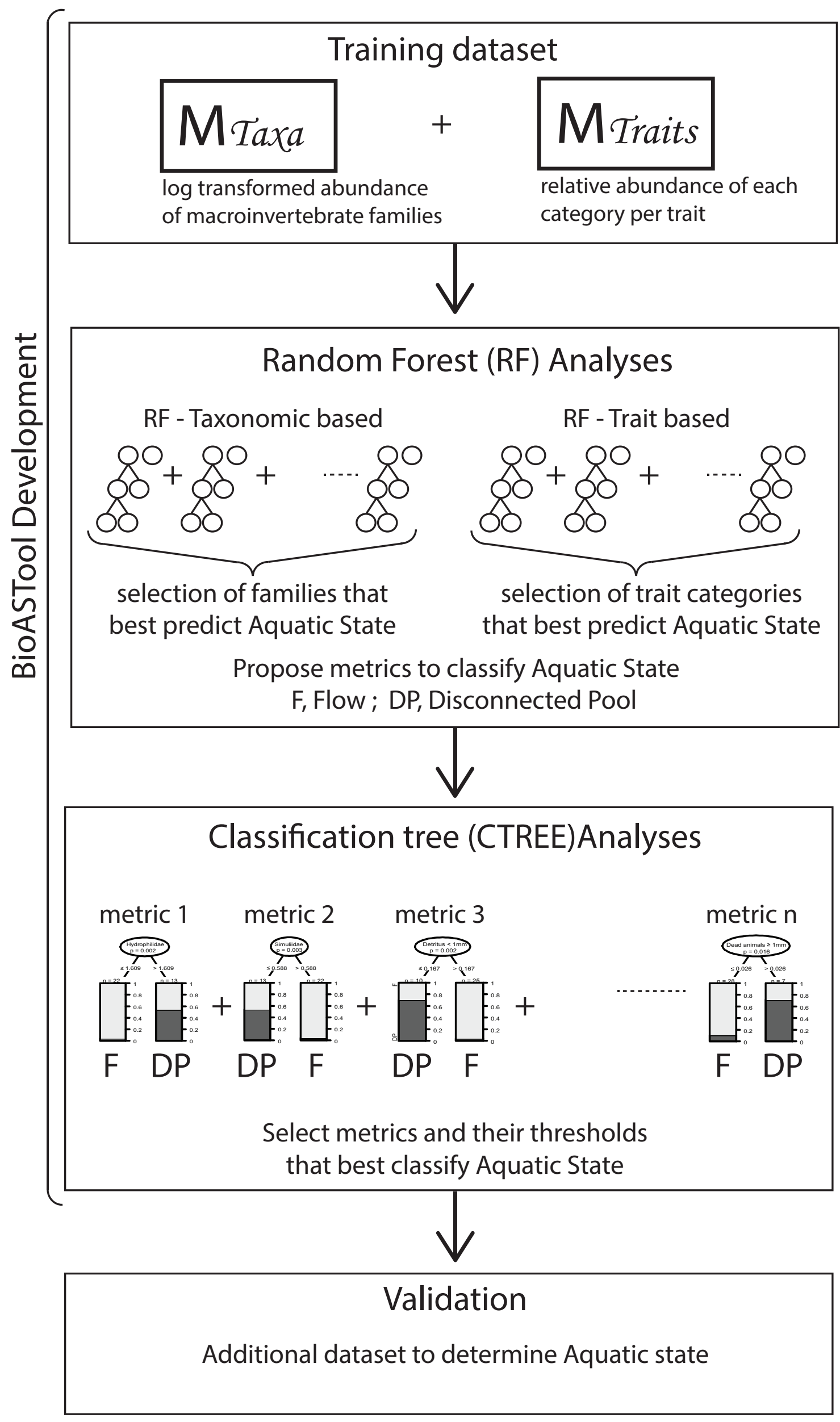




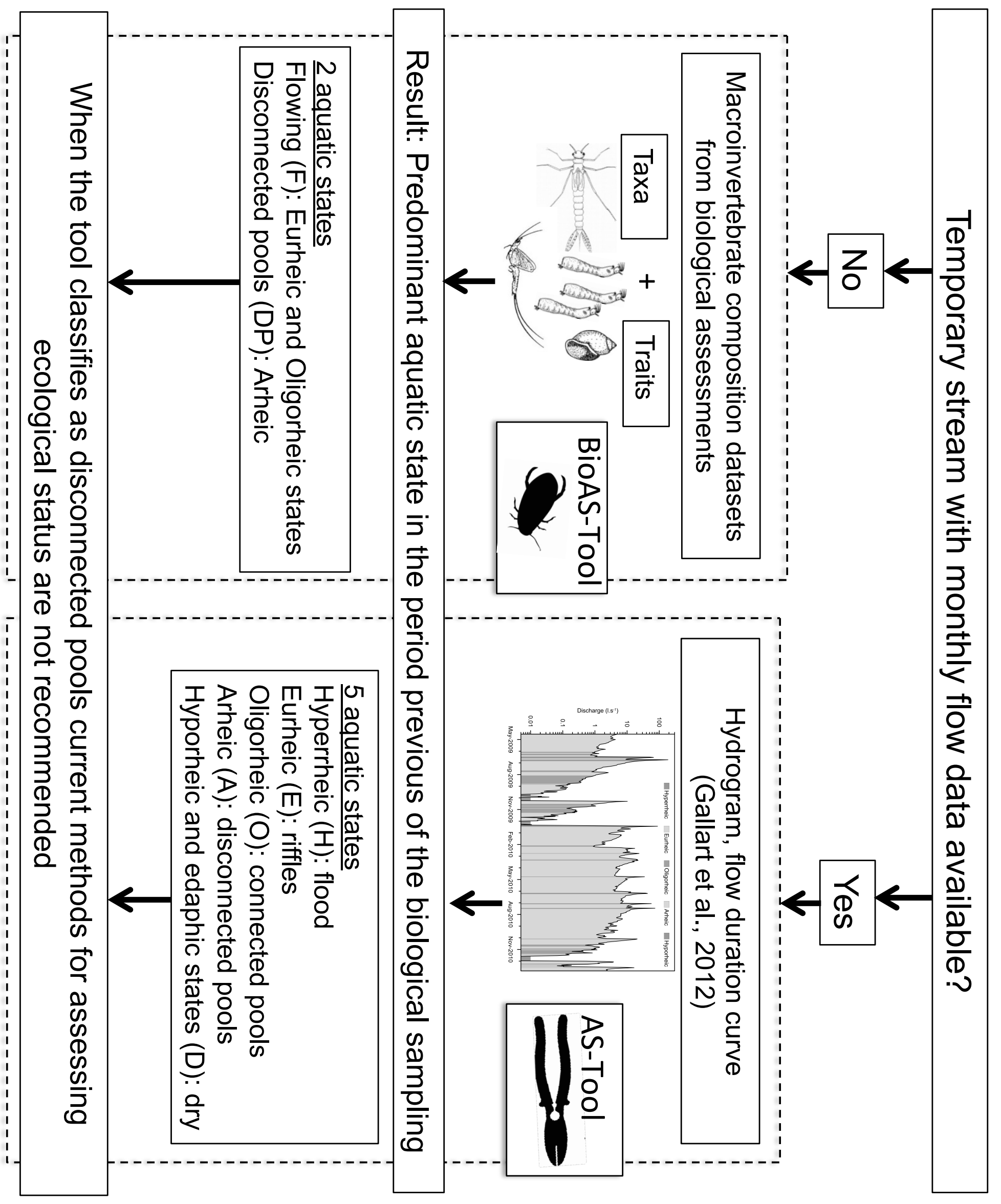


(a)

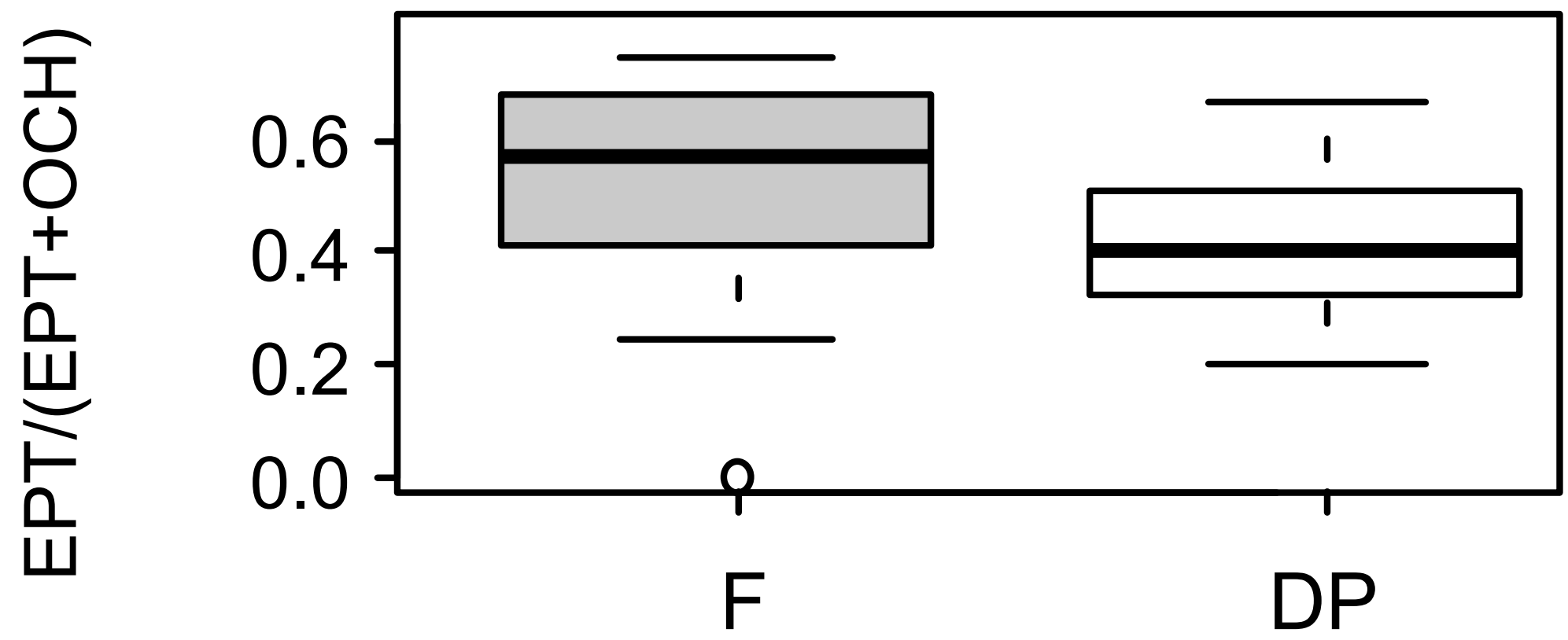

(b)

Ш
士

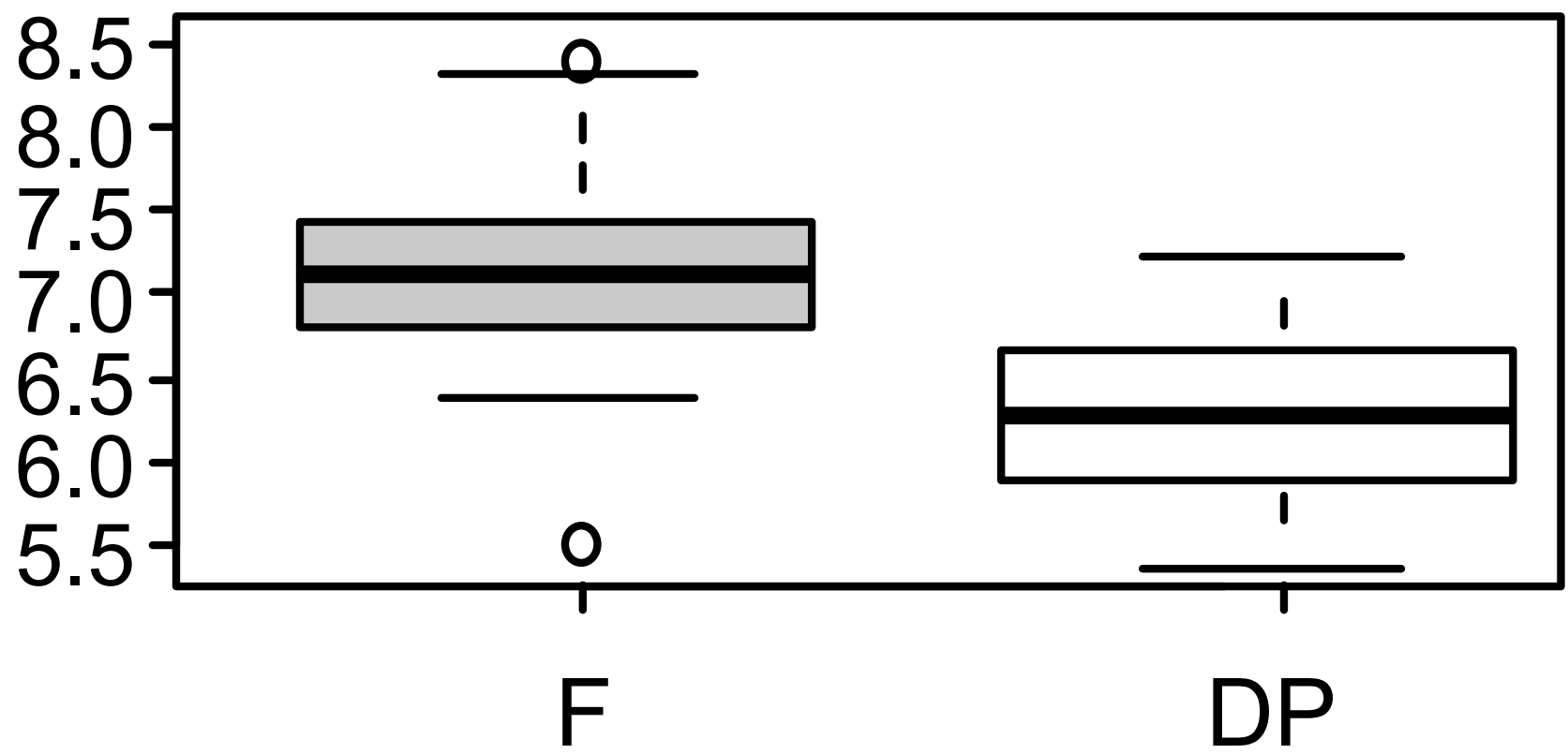




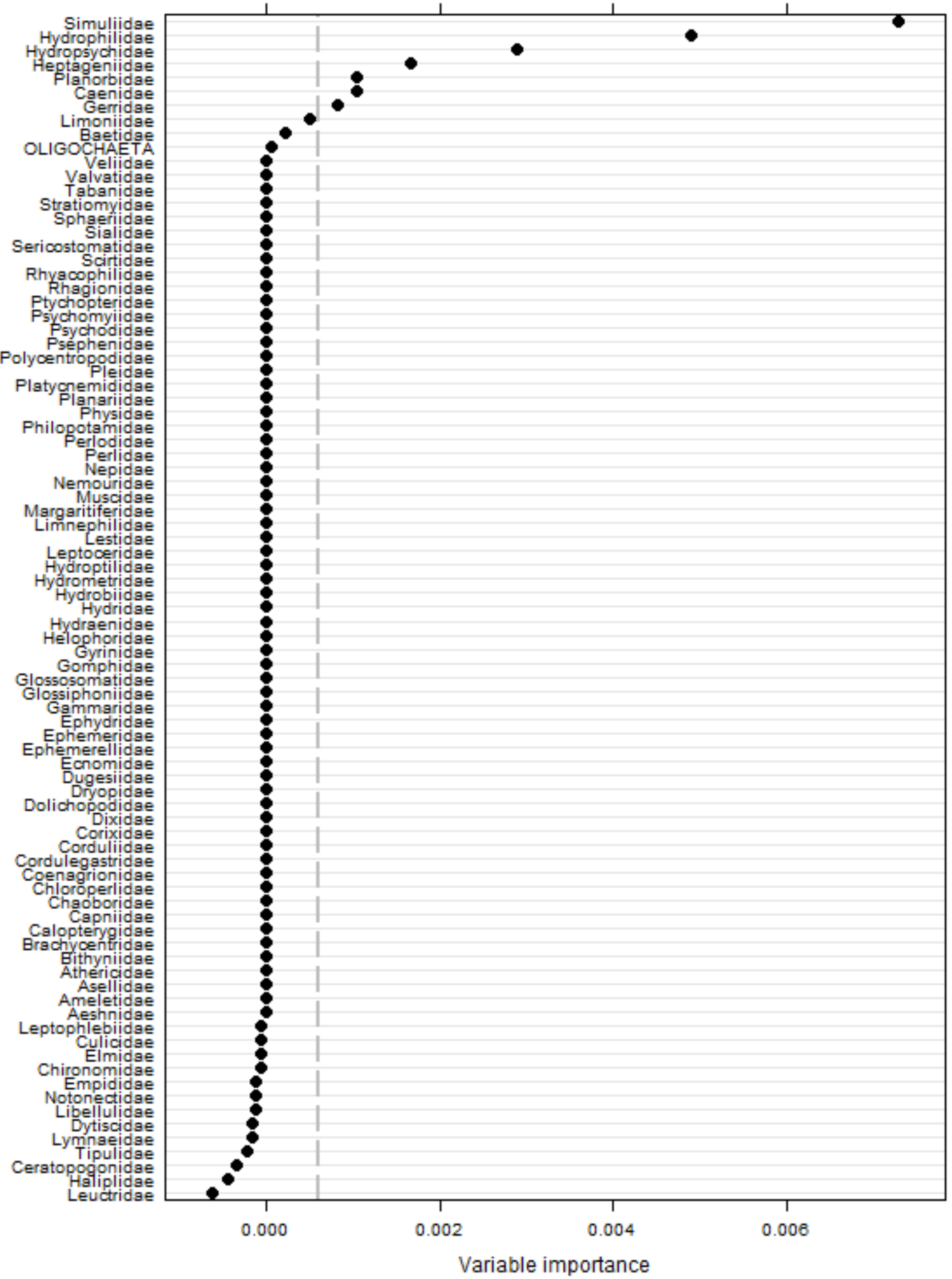




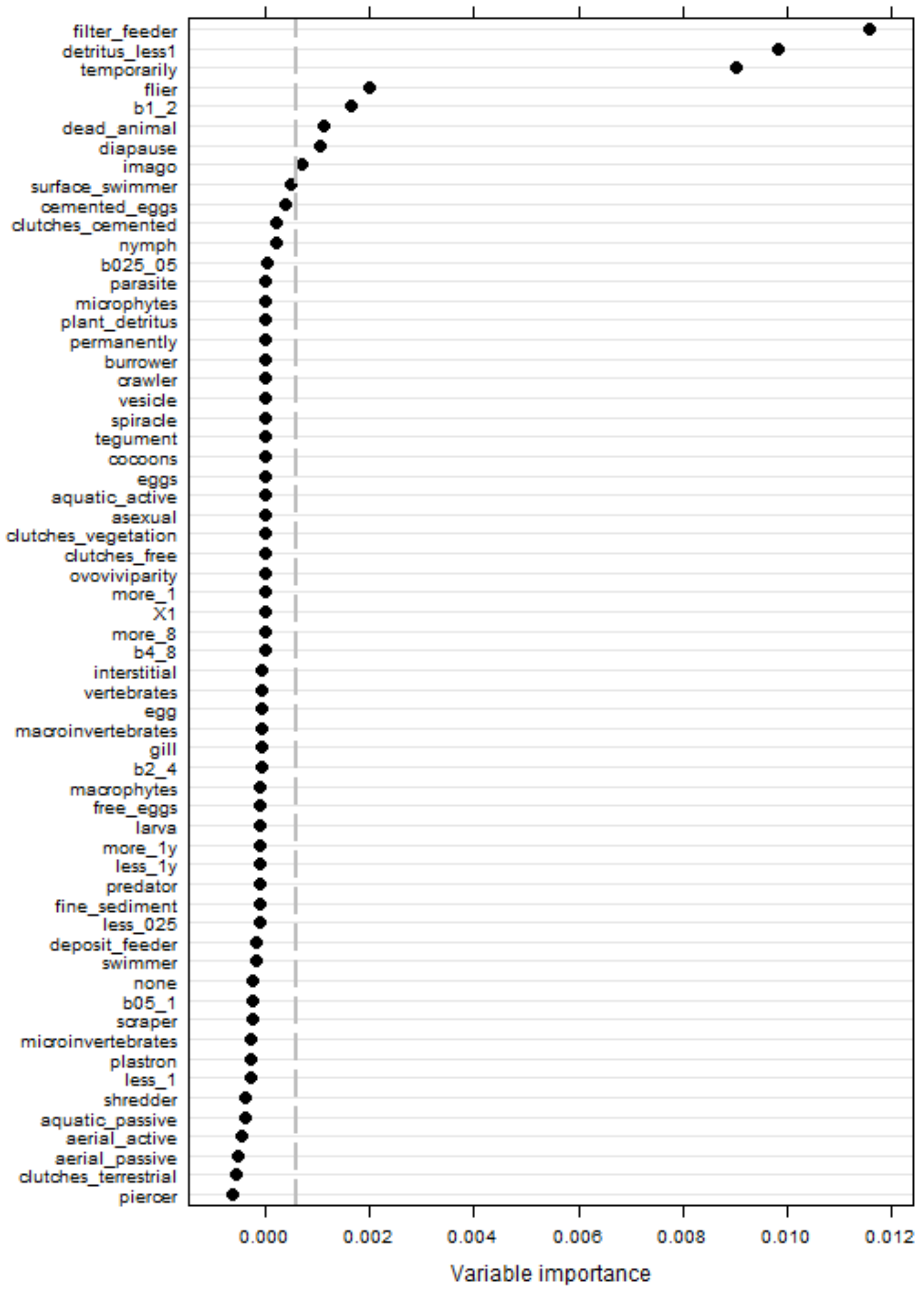



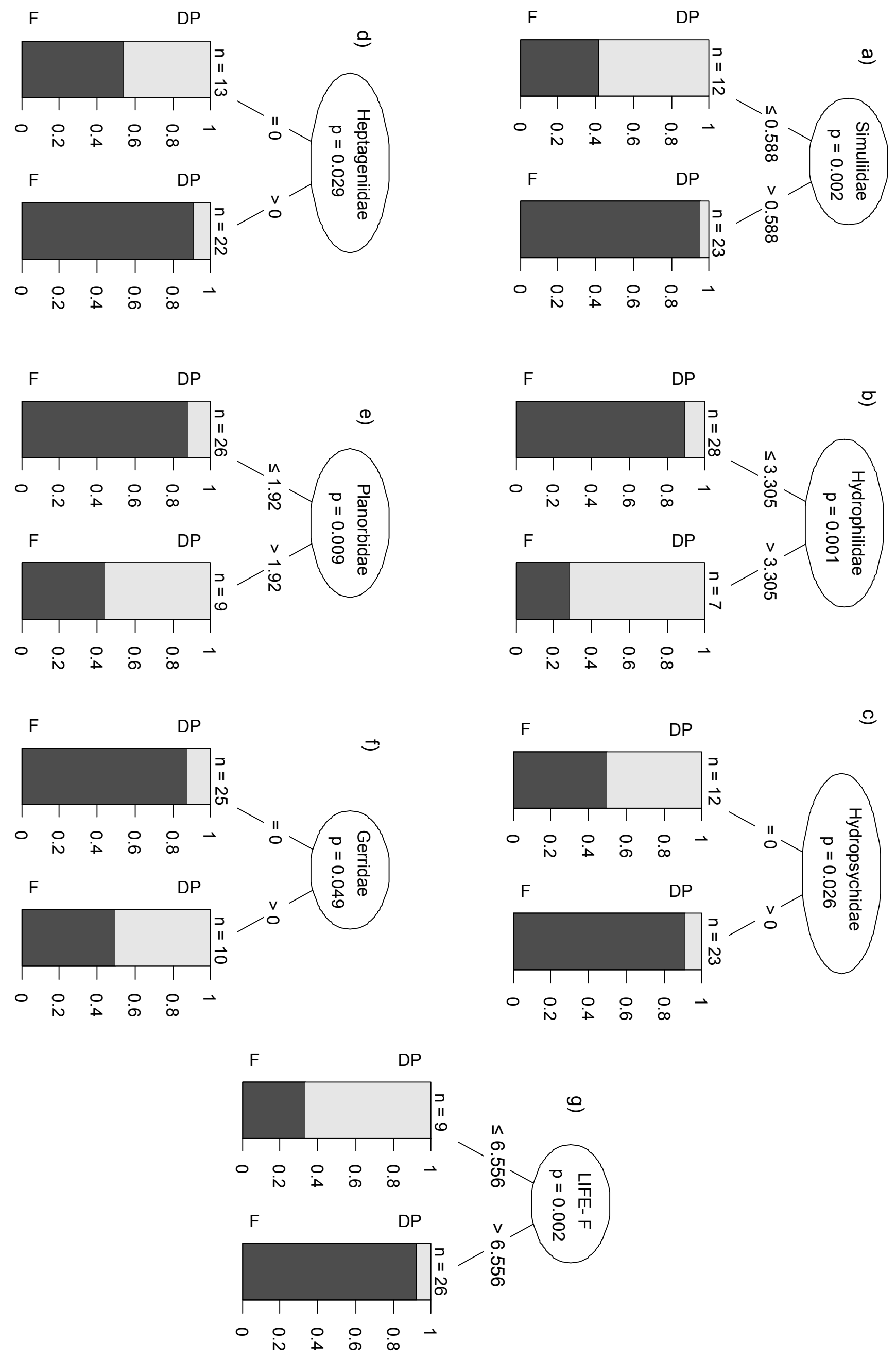

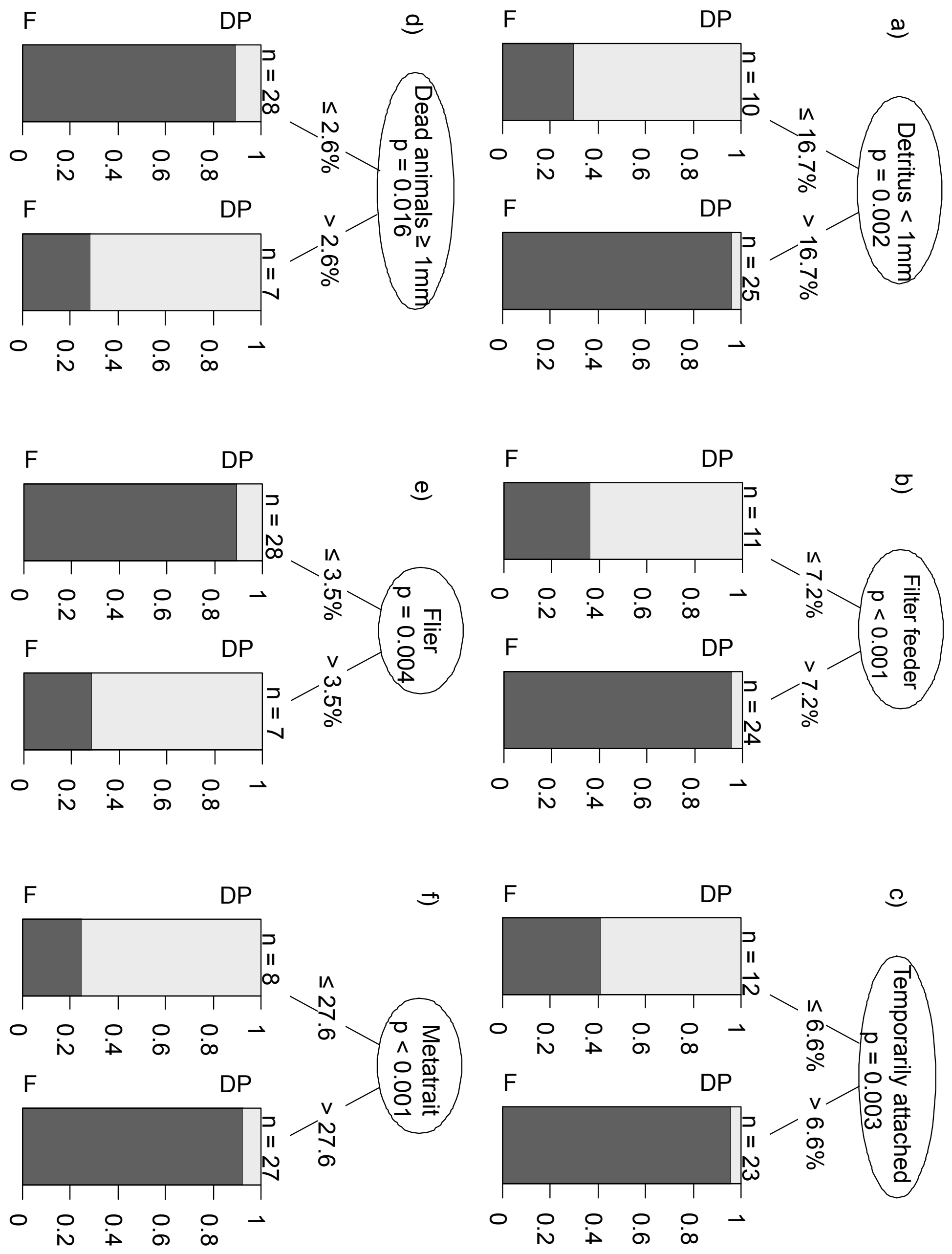
(a)

(b)
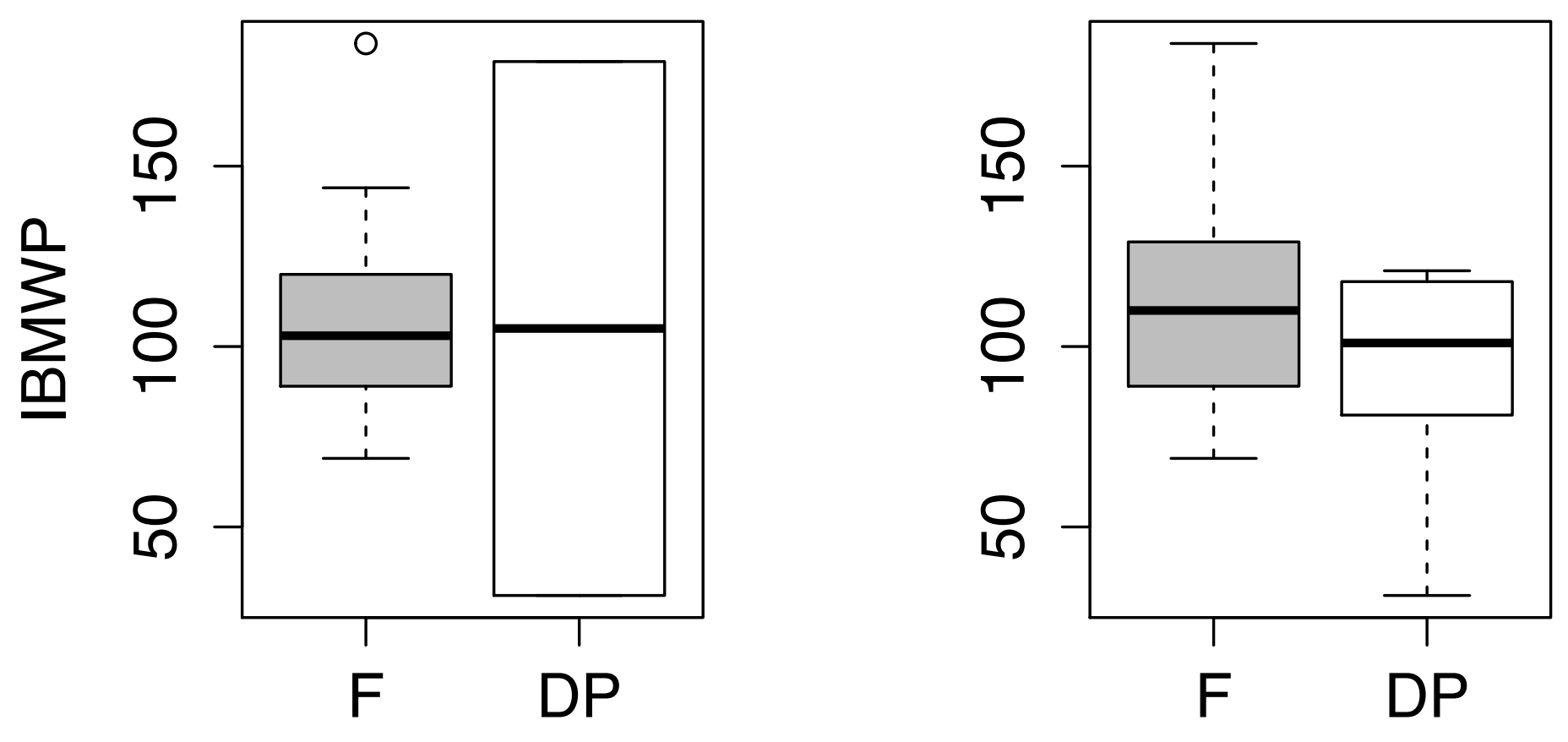